T. JUNG*\#, W. KWAŚNY*, Z. RDZAWSKI**, W. GŁUCHOWSKI**,

K. MATUS*, M. PAWLYTA*, M. SZINDLER*

\title{
CHANGES IN STRUCTURE OF CuCr0.6 ALLOY AFTER REPETITIVE CORRUGATION PROCESS
}

\begin{abstract}
This paper presents the study of repetitive corrugation process influence on the strengthening of annealed alloy. Based on the results of mechanical properties of deformed sample, it has been found that the microhardness, ultimate tensile strength, yield strength and apparent elastic limit are significantly increased in relation to annealed sample. Examination on transmission electron microscopy confirmed the effect of intensive plastic deformation on structure fragmentation in the nanometric scale. This work confirmed the possibility of using the repetitive corrugation process to increase mechanical properties of CuCr0.6 alloy.

Keywords: CuCr0.6 alloy, severe plastic deformation, repetitive corrugation and straightening, electron backscatter diffraction, transmission electron microscopy.
\end{abstract}

\section{Introduction}

Nowadays, material engineering is increasingly focusing on the development of methods which can offer continuous production of ultrafine grained [1,2] and bulk nanostructured materials $[3,4]$. Such materials usually have higher hardness and strength due to a very high level of fragmentation in comparison to conventional grain size metals and alloys [5,6]. A modern group of metalworking techniques that can provide ultrafine and bulk nanostructured is severe plastic deformation (SPD). One group of material that can be processed using severe plastic deformation is copper and its alloys. In that case strengthening mechanisms may be introduced through a large extent by chemical composition (precipitation hardening) as well as by intensive deformation. The most popular methods of SPD deformation are equal channel angular pressing (ECAP), accumulative roll-bonding (ARB), high-pressure torsion (HPT) or repetitive corrugation and straightening (RCS) [7]. An important advantage of the RCS method is the opportunity to plan the order of use of individual rolls in the process of deformation. That gives the possibility of production line optimization and apply this method for industrial scale. The RCS process, to some extent, is similar to the conventional rolling process. The difference concern the shape and location of the rollers which allow folding the material in a specific way $[8,9]$. Previous work $[9,10]$, where toothed rollers were used to transverse bending and classic rollers for straightening of the material, confirmed that RCS process effectively reduce the grain size of $\mathrm{CuCr} 0.6$ and $\mathrm{CuNi} 2 \mathrm{Si} 1$ alloys strips. $\mathrm{RSC}$ pro- cess proved to be also a more efficient method for structure and mechanical properties modification of commercial $\mathrm{CuSn} 6$ alloy strip (semi-hard) as compared with the classic rolling process [11-13]. In that case the extra set of grooved rolls responsible for the folding in the direction of rotation of the rollers was additionally used. This paper discusses the effect of intensive deformation in the RCS process with similar configuration of rollers on mechanical properties and structure of the $\mathrm{CuCr} 0.6$ alloy.

\section{Material descriptions and research methodology}

Experiments were carried out on copper chromium alloy strips. The material was obtained from precipitation hardened copper alloy with $0.6 \%$ of chromium waste (chemical composition is shown in Table 1). The material was melted in an induction furnace and casted into moulds. Ingots were hot rolled down to $3 \mathrm{~mm}$ thickness strips. After mechanical removal of the oxides from the surface, strips were cold rolled down to $0.1 \mathrm{~mm}$ of thickness, cut to $20 \mathrm{~mm} \times 120 \mathrm{~mm}$ and annealed in a resistance furnace in a protective atmosphere of argon at $650^{\circ} \mathrm{C}$ during one hour. Next material was subjected to RCS process using 30 cycles of deformation consisting of repetitive bending by toothed and grooved rolls. After a predetermined number of deformation cycles, strips were straightened using classic rollers (sample after RCS process). As reference annealed sample before RCS process was used. Deformation process scheme was presented in figure 1.

\footnotetext{
SILESIAN UNIVERSITY OF TECHNOLOGY, FACULTY OF MECHANICAL ENGINEERING, INSTITUTE OF ENGINEERING MATERIALS AND BIOMATERIALS, 18A KONARSKIEGO STR., 44-100 GLIWICE, POLAND

** NON FERROUS METALS INSTITUTE, 5 SOWIŃSKIEGO STR., 44-100 GLIWICE, POLAND

\# Corresponding author: Tymoteusz.jung@polsl.pl
} 
TABLE 1

Chemical composition of $\mathrm{CuCr} 0.6$ alloy (CW105C)

\begin{tabular}{|c|c|c|c|c|}
\hline \hline \multicolumn{5}{|c|}{ Content [\% wt] } \\
\hline $\mathbf{C r}$ & $\mathbf{S i}$ & $\mathbf{F e}$ & Others & $\mathbf{C u}$ \\
\hline $0.5-1.2$ & $\max 0.1$ & $\max 0.08$ & $\max 0.2$ & balance \\
\hline
\end{tabular}

A

B

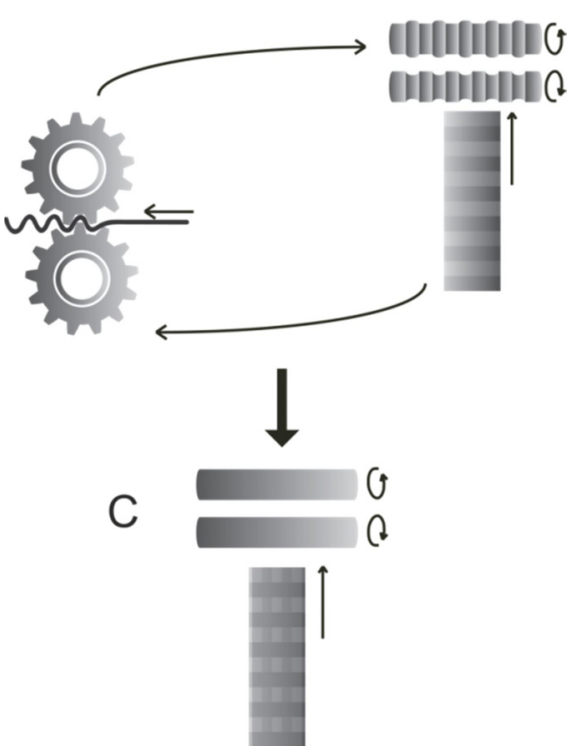

Fig. 1. RCS deformation process scheme: repetitive corrugation on toothed rolls (A) and grooved rolls (B) in each deformation cycle and final straightening on flat rolls $(\mathrm{C})$

For microhardness measurement Vickers's Future-Tech FM-ARS was applied, using a load of $50 \mathrm{~g}$ during the $15 \mathrm{~s}$. The measurement was performed on a longitudinal section of examined strips. The static tensile test was performed at room temperature on a universal testing machine Instron 4505 / $5500 \mathrm{~K}$ with a $1 \mathrm{kN}$ measuring sensor.

Structure analysis was performed on PANalytical X'Pert PRO diffraction system using filtered radiation from the cobalt lamp operating at $40 \mathrm{kV}$ voltage and $30 \mathrm{~mA}$ current. The $\mathrm{X}$-ray qualitative phase analysis of the investigated samples was conducted in the Bragg-Brentano geometry using a PIXcel 3D detector. An average subgrains size were calculated using Scherrer method (with silicon standard reference material used to measure the instrumental broadening) for four most intense diffraction lines. Residual stresses analysis was made using the $\sin 2 \psi$ technique (the X'Pert Stress software). Stress values were determined in parallel and perpendicular direction to the deformation process based on changes in interplanar distance for (311) diffraction line.

Samples for SEM studies have been prepared by mechanical and electrolytic polishing. Back-Scattered Electron (BSE) imaging, Energy-Dispersive X-ray spectroscopy (EDX) and Electron Backscatter Diffraction (EBSD) were conducted in a scanning electron microscope Zeiss Supra 35 with field emission gun, equipped with an EDAX software and a TSL OIM EBSD system. For statistics any point pair with misorientation exceeding $2^{\circ}$ was considered as boundary. The points with very low quality of the diffraction pattern (image quality IQ $<20 \%$ ) were excluded from the analysis. Such conditions mostly refer to precipitates of chromium, which during the electrolytic polishing behaved differently than the matrix material. A boundaries with angles less than $15^{\circ}$ were marked as low angle (green lines drawn on image quality maps), a boundaries with angles larger than $15^{\circ}$ were marked as high angle (blue lines). The twin boundaries were marked as a separate group (the angle between 59 and 61 degrees, marked as red). TEM investigations were performed in a probe Cs-corrected S/TEM Titan 80-300 FEI microscope equipped with EDAX EDS system. Observations were made on the thin foil cut parallel to the strip surface. Thin foil was roughly prepared by electrolytic polishing, then finished by ion beam polishing.

\section{Results and discussion}

In order to determine the mechanical properties, microhardness measurements and static tensile test were performed. The microhardness of the alloy after the intensive deformation by RCS process increase by about $40 \%$ (Tab. 2). Based on analysis of the results of static tensile test it was found that ultimate tensile strength also increase by $28 \%$, the yield strength by $89 \%$ and the apparent elastic limit by $46 \%$, which indicates the existence of strong strain hardening for material subjected to the RCS process. Fig. 2 presents a static tensile test curve of strip annealed and deformed in RCS process.

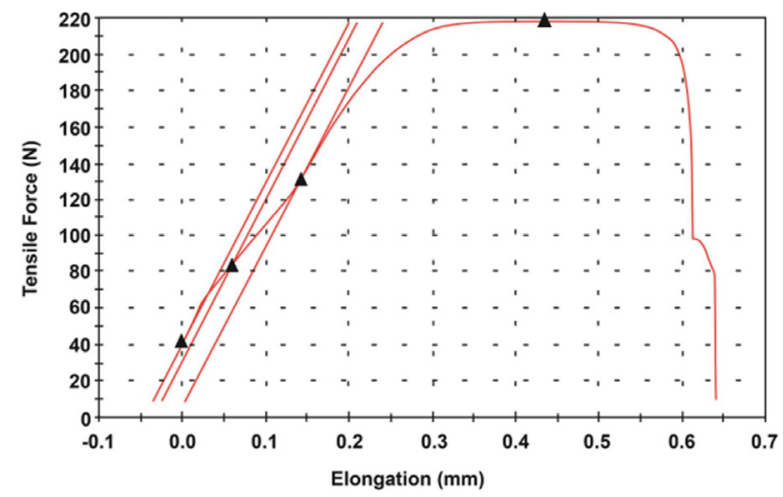

Fig. 2. Static tensile test curve of the strip annealed and deformed in RCS process

TABLE2

Mechanical properties of $\mathrm{CuCr} 0.6$ alloy before and after 30 cycles of RCS process

\begin{tabular}{|c|c|c|c|c|c|c|c|c|}
\hline \hline Sample & $\mathbf{H V}_{\mathbf{0 . 0 5}}$ & $\begin{array}{c}\text { Elong. } \\
{[\%]}\end{array}$ & $\begin{array}{c}\mathbf{F}_{\max } \\
{[\mathbf{N}]}\end{array}$ & $\begin{array}{c}\text { UTS } \\
{[\mathbf{M P a}]}\end{array}$ & $\begin{array}{c}\mathbf{F}_{\mathbf{0}, \mathbf{2}} \\
{[\mathbf{N}]}\end{array}$ & $\begin{array}{c}\text { YS } \\
{[\mathbf{M P a}]}\end{array}$ & $\begin{array}{c}\mathbf{F}_{\mathbf{0}, \mathbf{0 5}} \\
{[\mathbf{N}]}\end{array}$ & $\begin{array}{c}\mathbf{E L} \\
{[\mathbf{M P a}]}\end{array}$ \\
\hline $\begin{array}{c}\text { before RCS } \\
\text { process } \\
\text { (annealed) }\end{array}$ & $78 \pm 4$ & 13 & 171 & 264 & 69 & 107 & 58 & 89 \\
\hline $\begin{array}{c}\text { after RCS } \\
\text { process } \\
\text { (annealed } \\
\text { and } \\
\text { deformed) }\end{array}$ & $110 \pm 4$ & 6 & 218 & 337 & 131 & 202 & 84 & 130 \\
\hline
\end{tabular}


On experimental diffraction pattern only diffraction lines typical for copper phase (ICSD database No. 98-062-7113) are visible (Fig. 3a). There are no diffraction lines characteristic for $\mathrm{Cr}$ phase due to the low amount of this element in the alloy. The average size of subgrains was determined by analysis

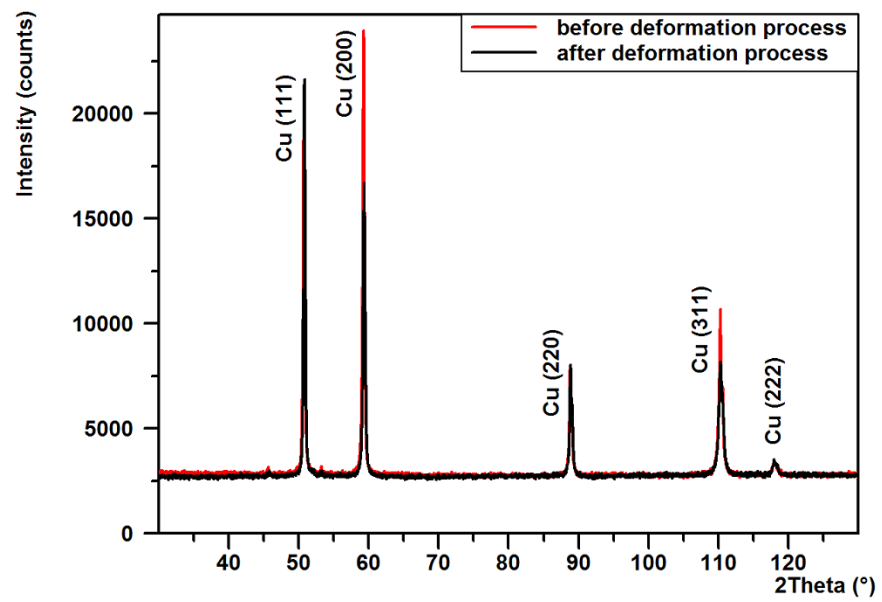

a)

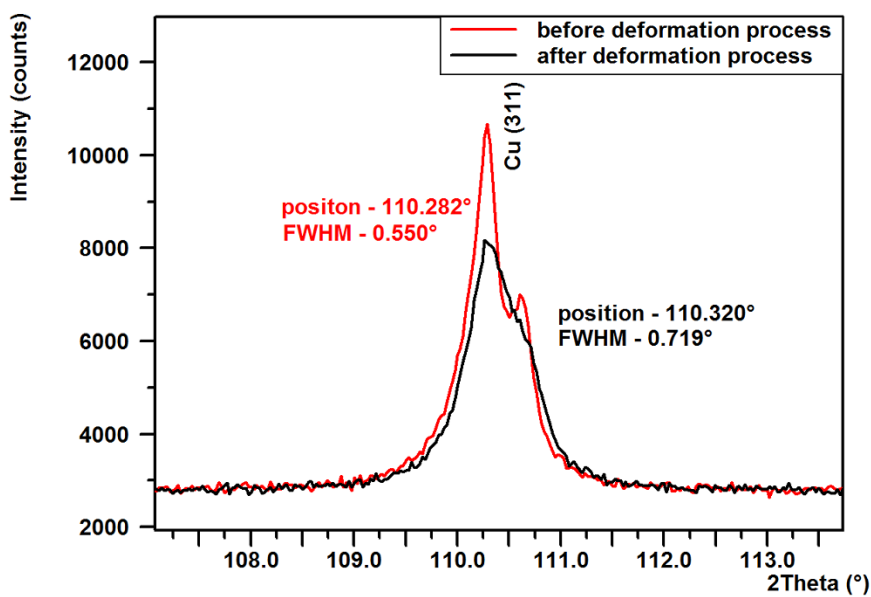

b)

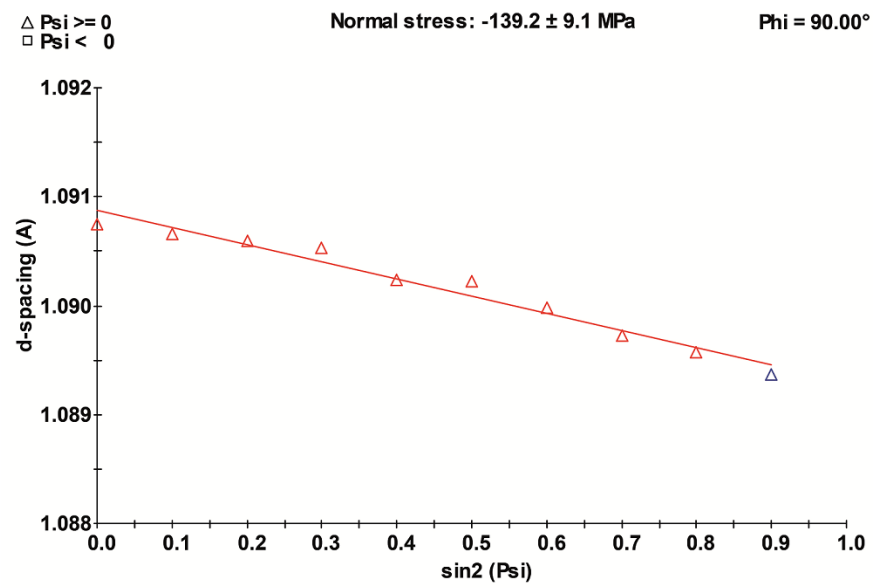

c)

Fig. 3. XRD pattern of $\mathrm{CuCr} 0.6$ alloy before and after 30 cycles of RCS process (a), magnification of the (311) diffraction lines (b), stress measurement results of $\mathrm{CuCr} 0.6$ alloy after 30 cycles of RCS process (c) of the broadening (full width at half maximum - FWHM) of main reflections lines (Fig. 3b). FWHM in all analyzed diffraction lines of annealed and deformed sample increased relative to annealed sample. Hence the average size of the subgrains was reduced from $80 \mathrm{~nm}$ in annealed sample to $68 \mathrm{~nm}$ in strip subjected to intensive deformation (Tab. 3). Analysis of the residual stress distribution indicates the compressive stresses for the longitudinal (Fig. 3c) and transverse directions. The compressive stresses significantly increased in material subjected to the RCS process, what may cause microhardness growth of the deformed strips.

TABLE 3

Residual stress and average subgrains size of $\mathrm{CuCr} 0.6$ alloy before and after 30 cycles of RCS process

\begin{tabular}{|c|c|c|c|}
\hline \multirow[b]{2}{*}{ Sample } & \multirow{2}{*}{$\begin{array}{c}\text { Average } \\
\text { subgrains } \\
\text { size } \\
\text { [nm] }\end{array}$} & \multicolumn{2}{|c|}{$\begin{array}{c}\text { Stress results } \\
{[\mathrm{MPa}]}\end{array}$} \\
\hline & & $\begin{array}{l}\text { Straight direction } \\
\text { to the process } \\
\text { direction }\end{array}$ & $\begin{array}{l}\text { Cross direction to } \\
\text { the process } \\
\text { direction }\end{array}$ \\
\hline $\begin{array}{c}\text { before RCS } \\
\text { process (annealed) }\end{array}$ & $80 \pm 6$ & $-111 \pm 16$ & $-125 \pm 23$ \\
\hline $\begin{array}{c}\text { after RCS process } \\
\text { (annealed } \\
\text { and deformed) }\end{array}$ & $68 \pm 5$ & $-139 \pm 9$ & $-216 \pm 21$ \\
\hline
\end{tabular}

The SEM backscattered electron observation of the surface of longitudinal section after electrolytic polishing revealed the presence of numerous chromium precipitations (Fig. 4). $\mathrm{Cr}$ precipitates are micrometers in size and are diversified regarding size and shape.

Figs. 5 and 6 present the EBSD results obtained for $\mathrm{CuCr} 0.6$ alloy before and after the RSC process. The range of the mapping in both cases was the same (about $35 \mu \mathrm{m} \times 35 \mu \mathrm{m}$ ). Image quality IQ maps are constructed from electron backscatter diffraction data. The contrast in these maps has different sources, mainly connected with grain boundary and strain contrast. Areas with low quality diffraction signal (IQ $<20 \%$ ) were excluded from further analysis and marked in black. These are the places of occurrence of chromium precipitates. The obtained orientation and distribution map allowed to determine the size and shape of the copper grains, which vary in terms of size (several hundred nanometers to more than 10 micrometers). The occurrence of annealing twins is typical for analyzed material. Prior to the RCS process, grains were regular shape and after the process, the grains were more irregular. The average grain size changes from $5.1 \pm 1.6$ microns to $3.8 \pm 1.2$ microns (Fig. 7). Table 4 shows a comparison of the boundaries concentration (length per unit area of tested specimens). The total length of the boundaries increased by $40 \%$. It can be noticed that the length of the twin boundaries (annealing twins) remains unchanged. Observed refinement of structure and increase share of the low-angle boundaries after intensive deformation process are consistent with the previous results obtained by this alloy [8-10].

In spite of micrometer size of grains, material shows good mechanical property, as a result of a significant number 


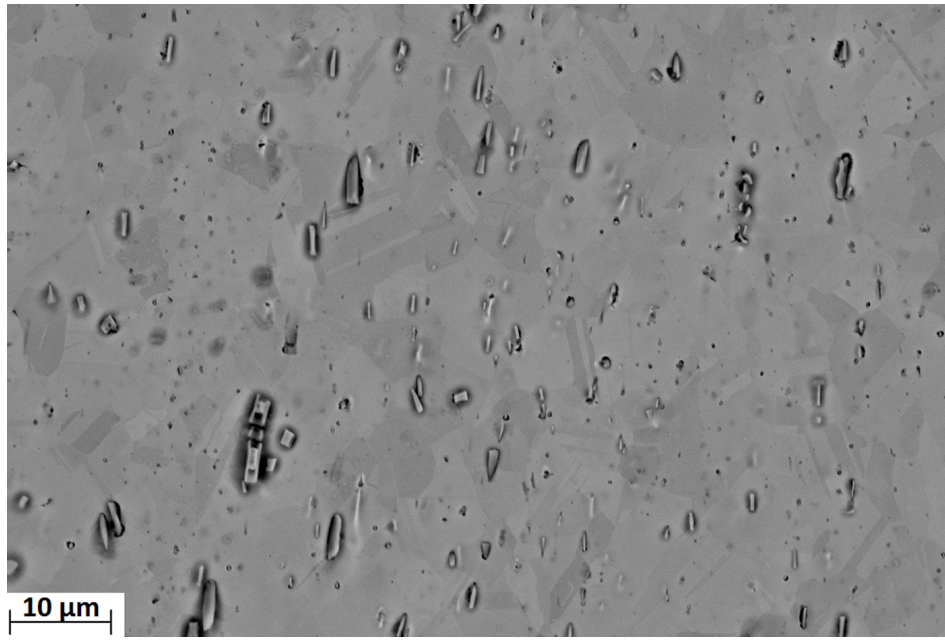

a)

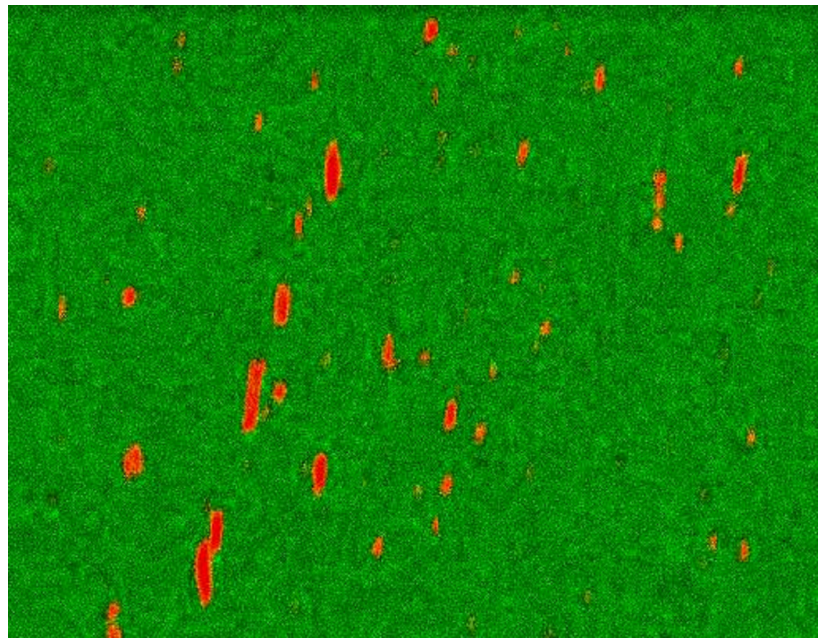

b)

Fig. 4. (a) SEM backscattered electron image of the annealed CuCr0.6 alloy (sample before RCS process). (b) The corresponding elemental maps $(\mathrm{Cu}-$ green, $\mathrm{Cr}-\mathrm{red})$

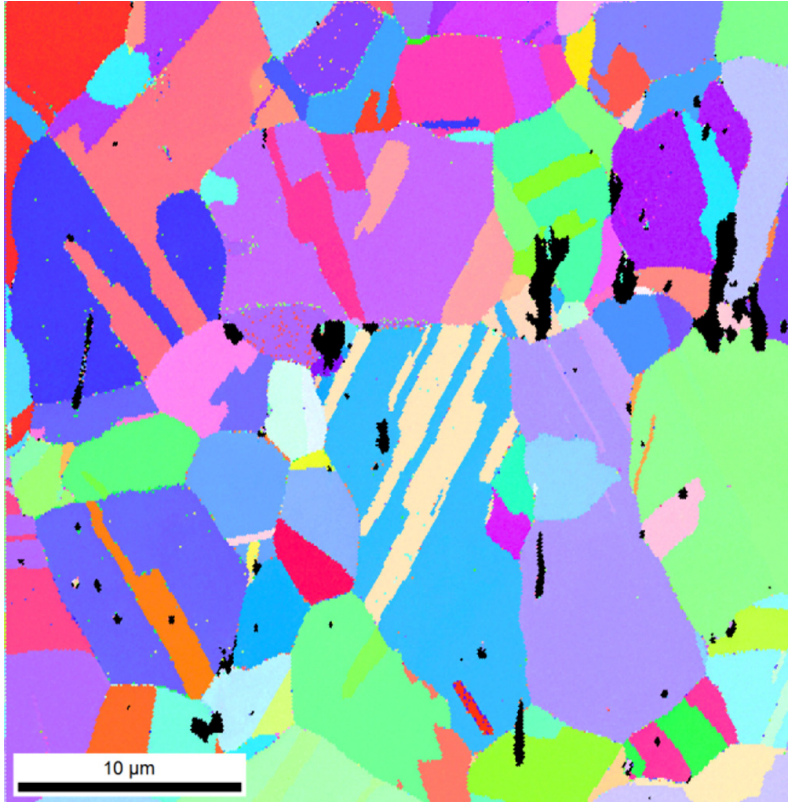

a)

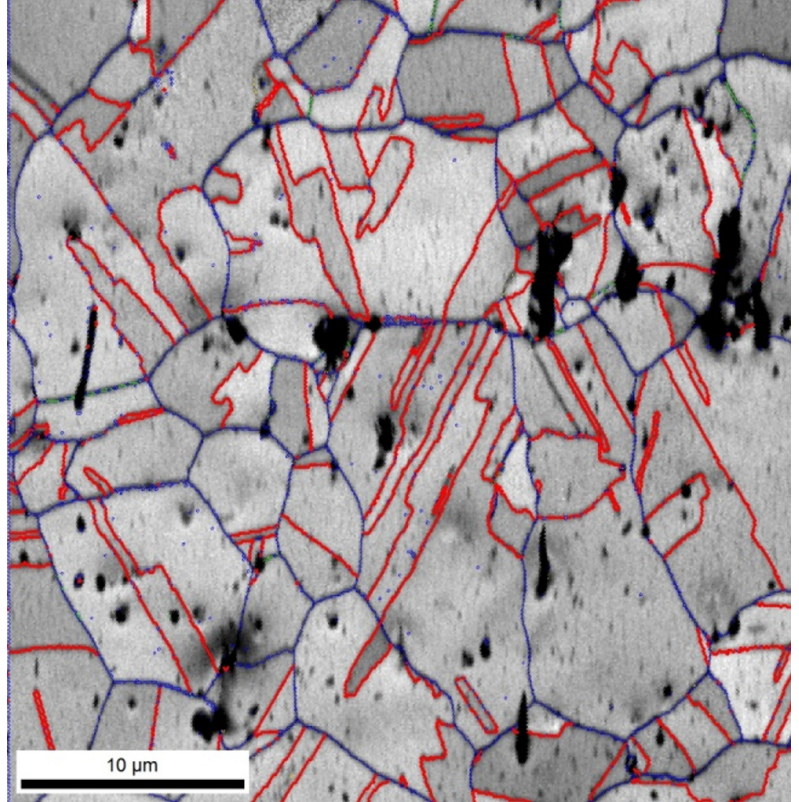

b)

Fig. 5. EBSD orientation (a) and image quality (b) maps of the annealed CuCr0.6 alloy (sample before RCS process)

TABLE 4 of microstructural features, such as subgrains and mosaic

Grain boundary character distributions of $\mathrm{CuCr} 0.6$ alloy before and after 30 cycles of RCS process

\begin{tabular}{|c|c|c|c|c|}
\hline \multirow{2}{*}{ Sample } & \multicolumn{2}{|c|}{ Surface density of grain boundary $\left[\boldsymbol{\mu m} / \boldsymbol{\mu m}^{\mathbf{2}}\right]$} \\
\cline { 2 - 5 } & Total & $\begin{array}{c}\text { Low-angle } \\
(<\mathbf{1 5}) \text { grain } \\
\text { value }\end{array}$ & \multicolumn{2}{|c|}{$\begin{array}{c}\text { High-angle grain } \\
\text { boundaries } \\
\left(>\mathbf{1 5}^{\circ}\right)\end{array}$} \\
\cline { 4 - 5 } & & 0.04 & 0.66 & 0.49 \\
\hline $\begin{array}{c}\text { before RCS } \\
\text { process (annealed) }\end{array}$ & 1.17 & All & $\begin{array}{c}\text { Annealing twins } \\
\mathbf{5 9 - 6 1 ^ { \circ }}\end{array}$ \\
\hline $\begin{array}{c}\text { after RCS process } \\
\text { (annealed } \\
\text { and deformed) }\end{array}$ & 1.66 & 0.12 & 1.09 & 0.45 \\
\hline
\end{tabular}
structures domain separated by low-angle boundaries. Such strengthening mechanisms also occur with other SPD techniques such as GP (groove pressing) or ECAE (equal channel angular extrusion), what has been proved in other publications [14-15]. Expanded subgrains structures also can be obtained by using ARB (accumulative roll bonding), HE (hydrostatic extrusion) or ECAP (equal channel angular pressing) methods [16]. Fig. 8 shows the TEM images obtained in the light and dark field, confirming the highly fragmented structure of the tested material. Visible subgrains have a diameter of several dozen nanometers.

A very effective tool to characterize the structure of the analyzed material was a STEM microscopy. BF images obtained in 


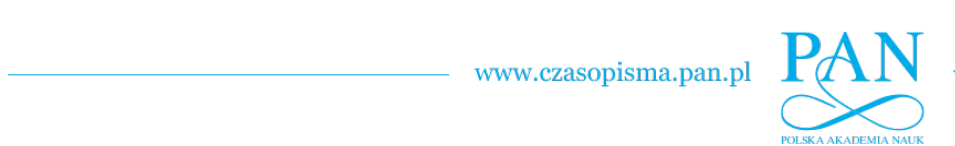

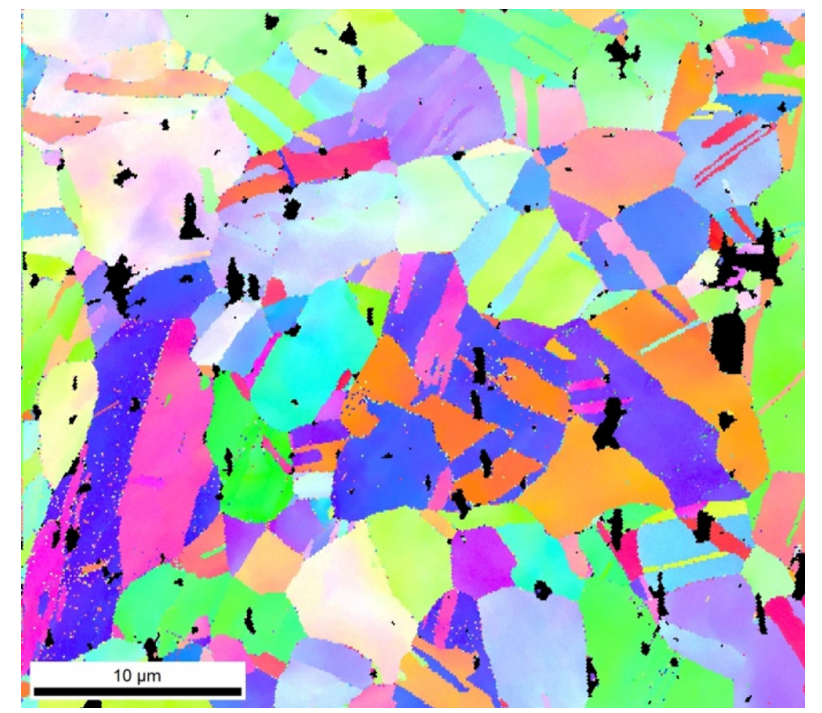

a)

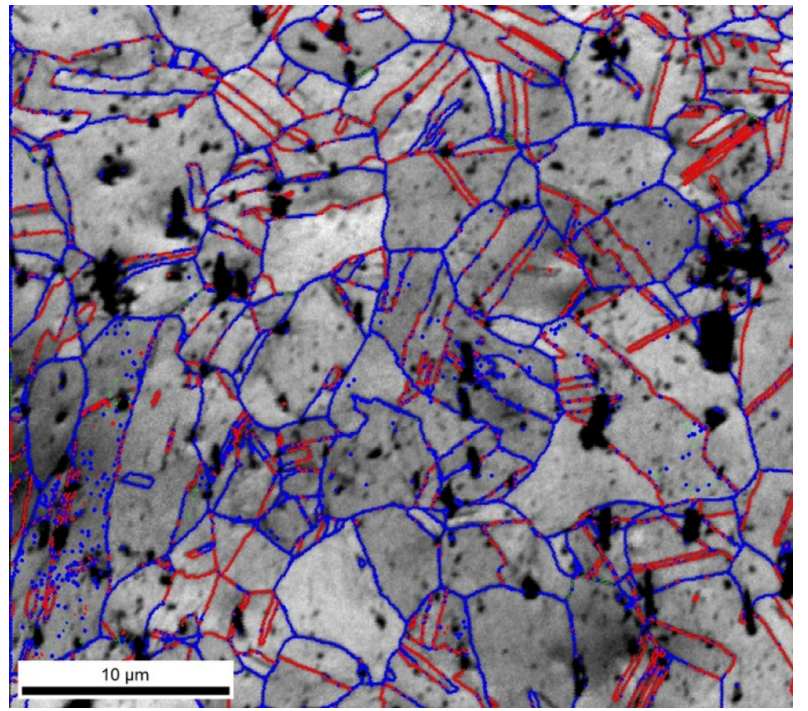

b)

Fig. 6. EBSD orientation (a) and image quality (b) maps of the annealed and deformed CuCr0.6 alloy (sample after RCS process)

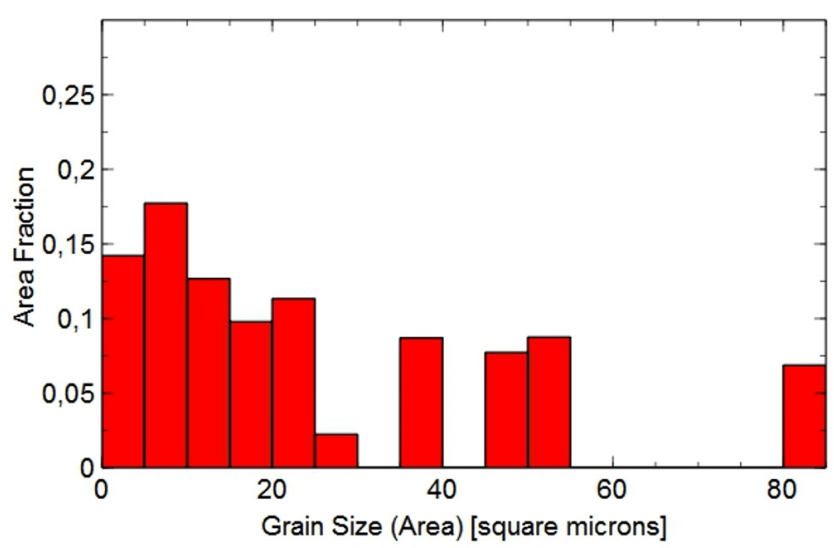

a)

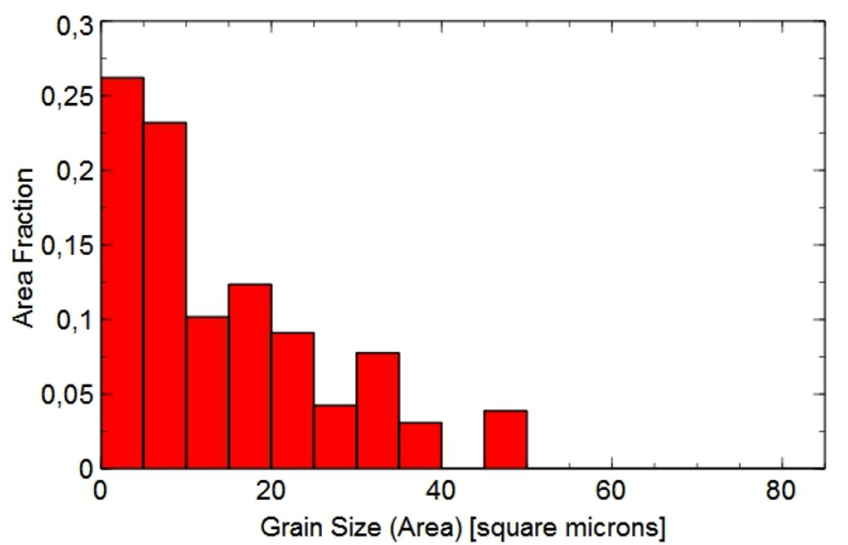

b)

Fig. 7. Comparison of grains size of the $\mathrm{CuCr} 0.6$ alloy before (a) and after 30 cycles of RCS process (b)

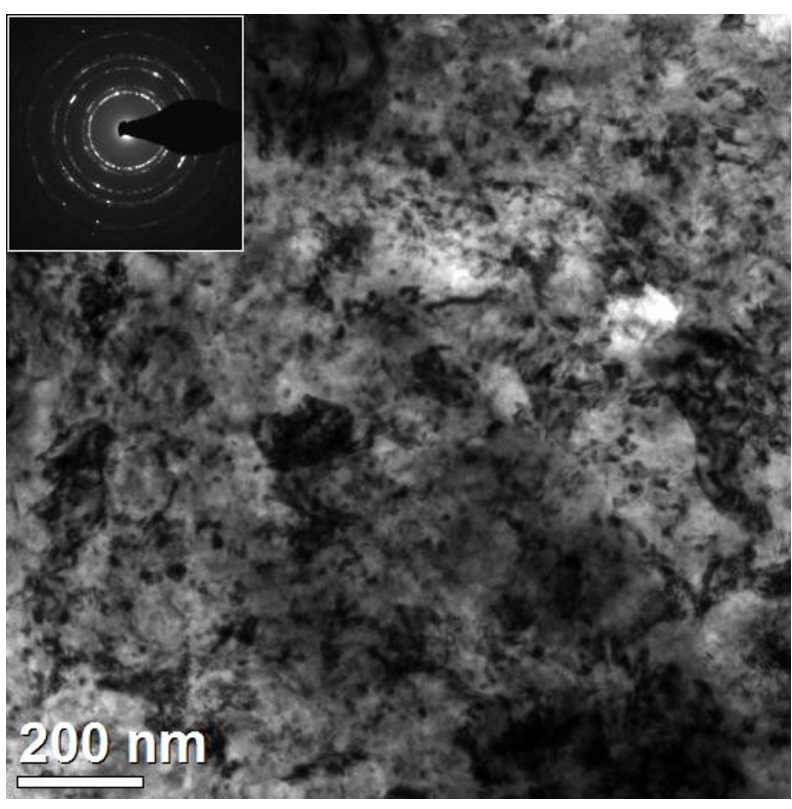

a)

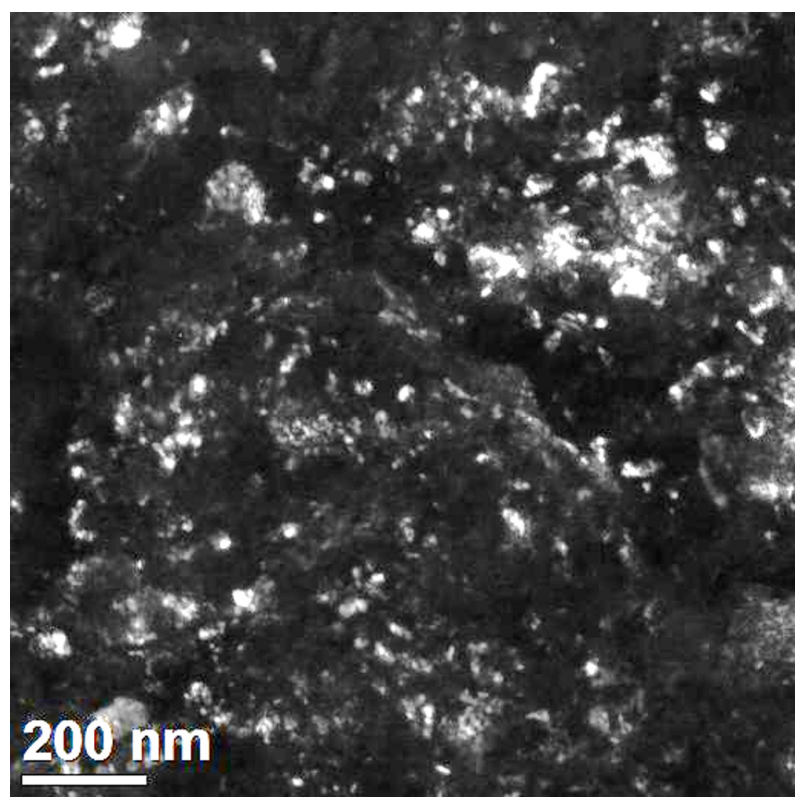

b)

Fig. 8. BF TEM image (a) and DF TEM image (b) of annealed CuCr0.6 alloy (sample before RCS process) 


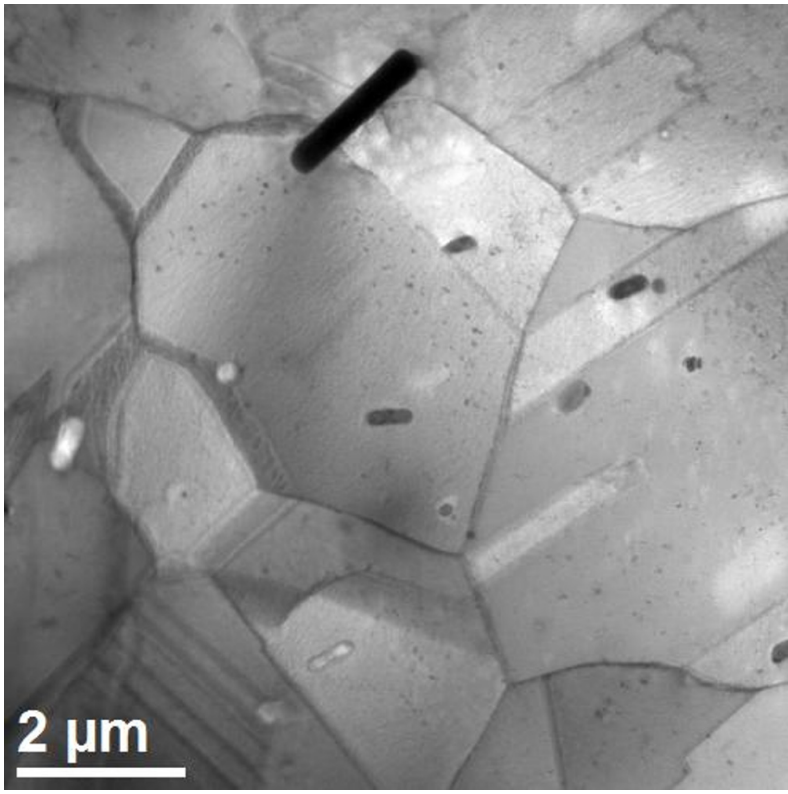

a)

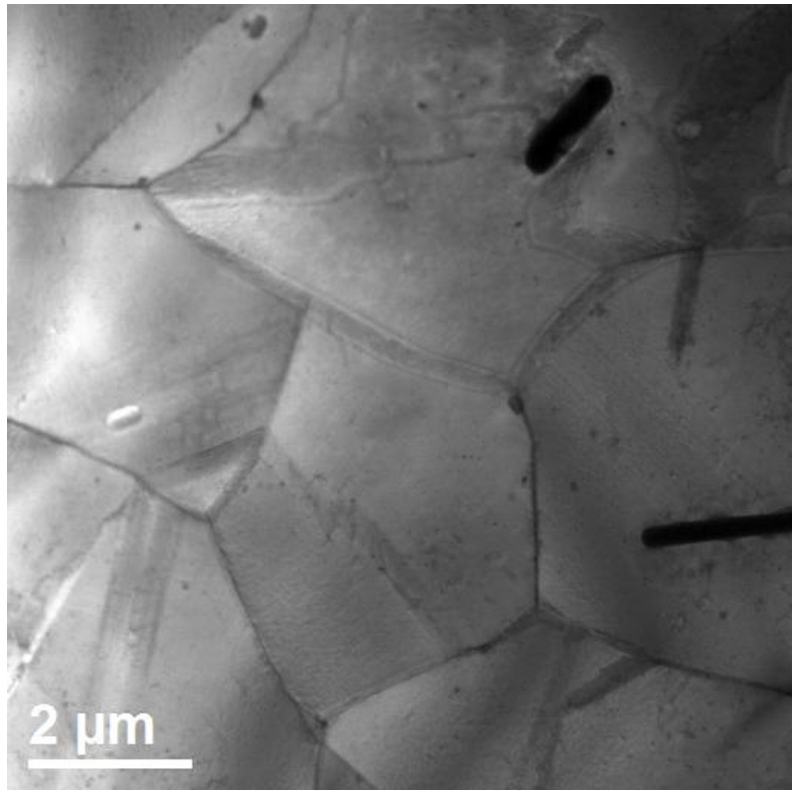

b)

Fig. 9. STEM-BF images of annealed $\mathrm{CuCr} 0.6$ alloy (sample before $\mathrm{RCS}$ process)

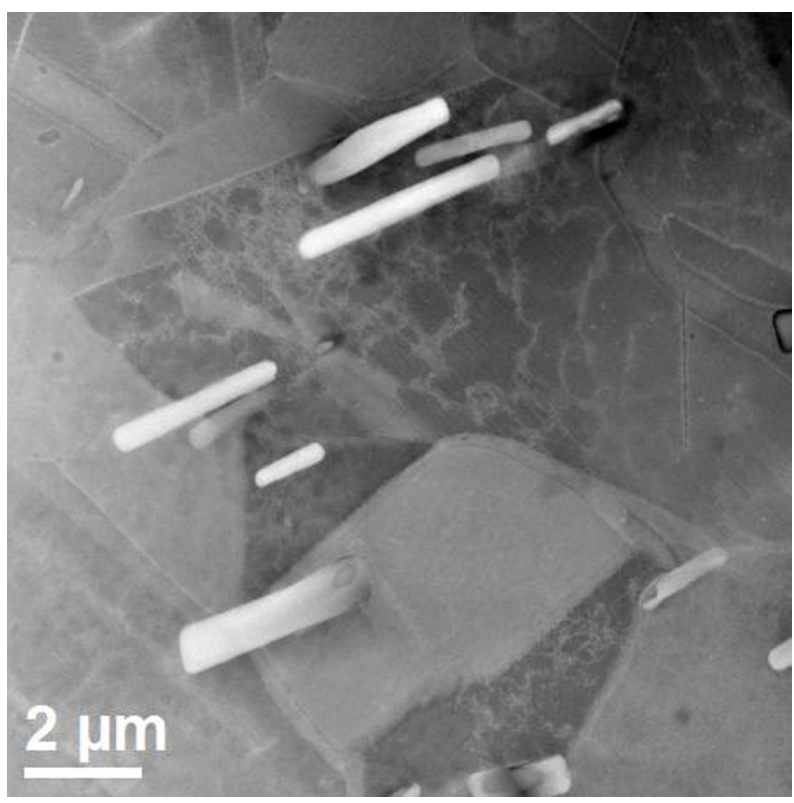

a)

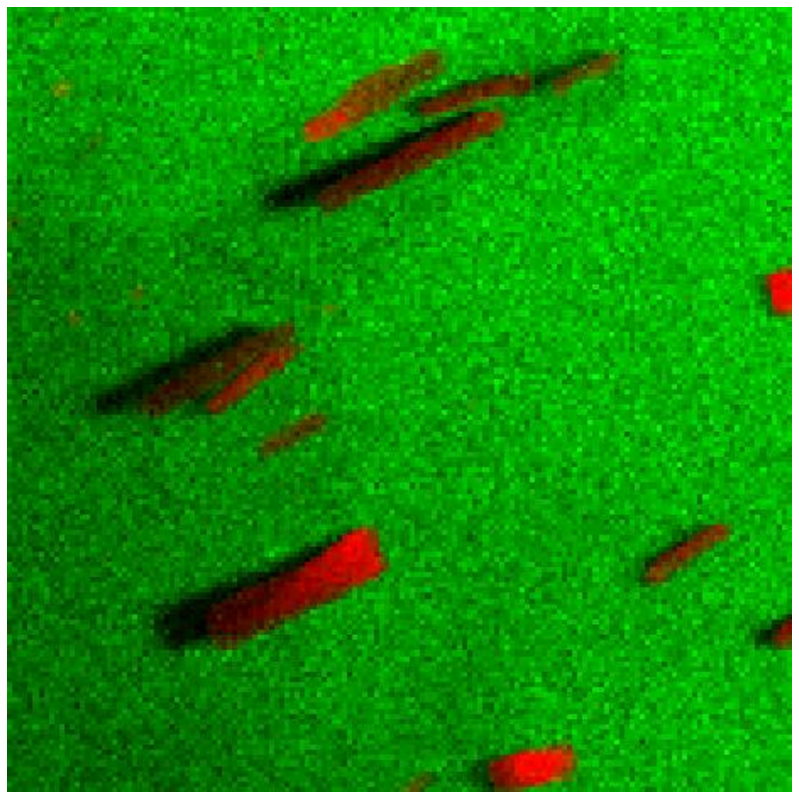

b)

Fig. 10. (a) STEM-HAADF image and (b) corresponding elemental map $(\mathrm{Cu}$ - green and $\mathrm{Cr}-\mathrm{red}$ ) of annealed $\mathrm{CuCr} 0.6$ alloy (sample before RCS process)

STEM mode are complementary to EBSD results (Fig. 9), show the grain boundaries and $\mathrm{Cr}$ precipitates. Cr precipitates presence was confirmed by chemical contrast visible on HAADF images (Fig. 10a) and mapping of chemical composition (Fig. 10b).

The basic difference in the $\mathrm{CuCr} 0.6$ alloy structure after the RCS process, is related to the emergence of a significant amount of dislocations that move within the grain and then lock itself, which leads to the formation of mosaic dislocation structure (Fig. 11). The mechanism of deformation is not uniform and long-range internal stress is generated by its gradient. The most characteristic features are uncondensed dislocation walls and dislocation cells. Dislocations occurred in the material before the RCS but after the process their number significantly increase. The size of the subgrains is from several dozen to hundreds of nanometers. In the microstructure after the RCS process slip bands are also very common (Fig. 12).

\section{Conclusions}

- The influence of the repetitive corrugation process on the $\mathrm{CuCr} 0.6$ alloy structure was confirmed. 


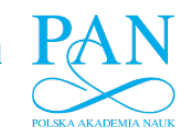

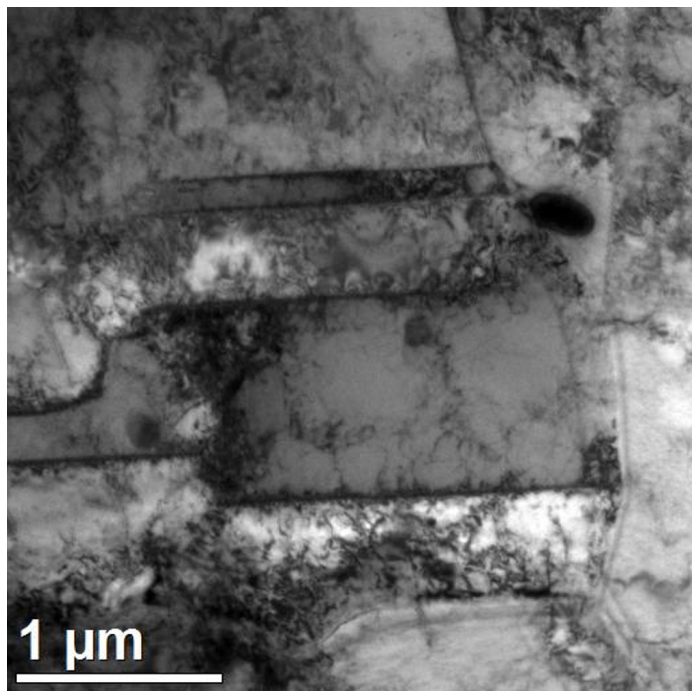

a)

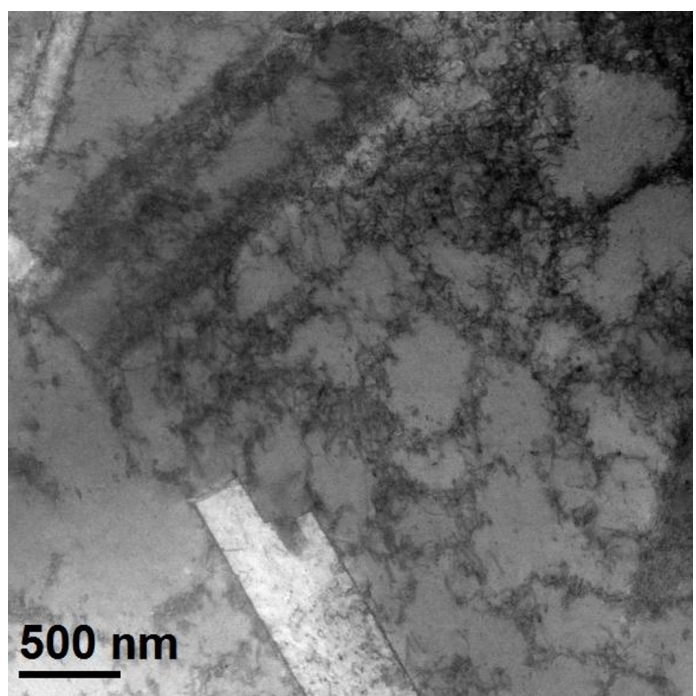

c)

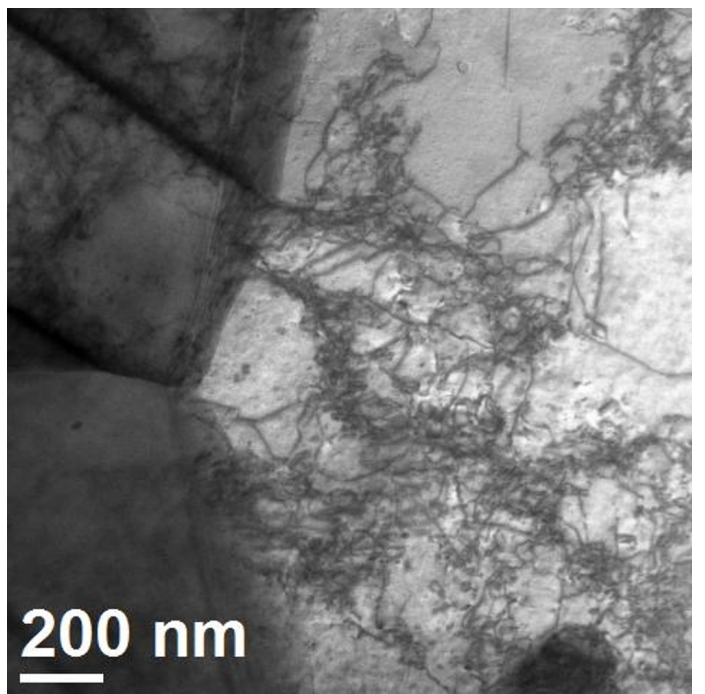

b)

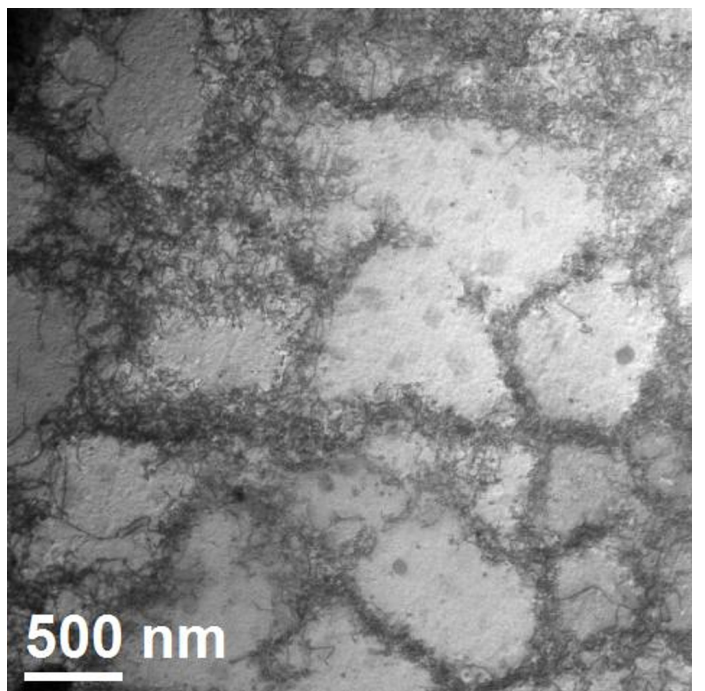

d)

Fig. 11. TEM-BF (a) and STEM-BF images (b-d) of the structure of annealed and deformed $\mathrm{CuCr} 0.6$ alloy (sample after RCS process), obtained with different magnifications

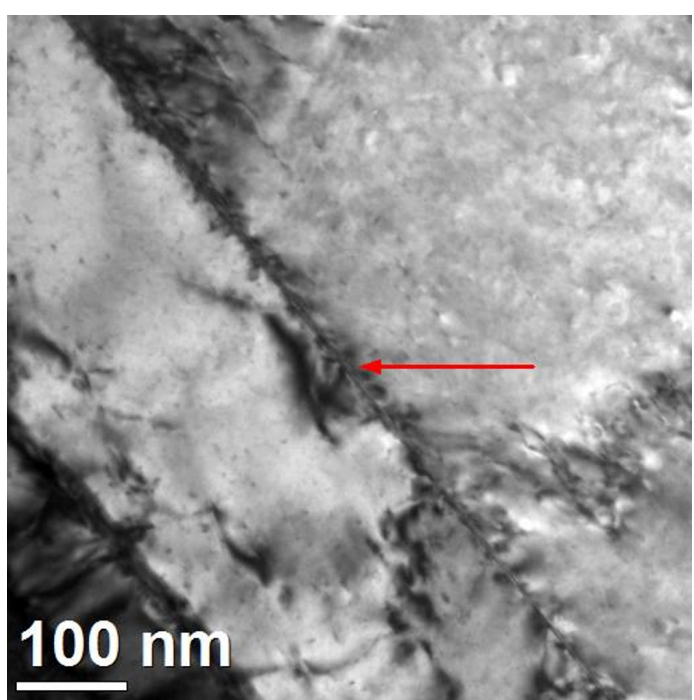

a)

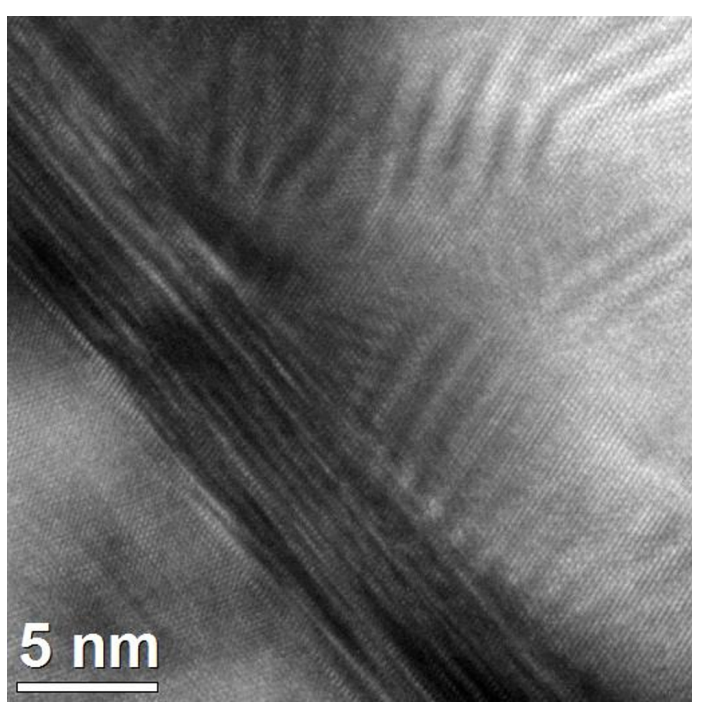

b)

Fig. 12. (a) BF TEM image of annealed and deformed $\mathrm{CuCr} 0.6$ alloy (sample after RCS process) and magnification of the part indicated by an arrow (b) 
- The EBSD examination allowed to determine that average grain size of the undeformed sample was $2.63 \mu \mathrm{m}$ and for the sample after RCS process is reduced to $1.75 \mu \mathrm{m}$. For the analyzed area, an increase in the length of the grain boundaries from $1.61 \mathrm{~mm}$ to $2.33 \mathrm{~mm}$ was also observed.

- On the basis of XRD studies it can be concluded that size of subgrains in annealed $\mathrm{CuCr} 0.6$ alloy after RCS process were reduced from 80 to $68 \mathrm{~nm}$. Mechanism responsible for the reduction of the average grain size (as well as for the strengthening of the alloy) was identify by TEM as formation of subgrains within the material.

\section{Acknowledgements}

This work was supported by the Ministry of Science and Higher Education of Poland as the statutory financial grant of the Faculty of Mechanical Engineering, Silesian University of Technology.

\section{REFERENCES}

[1] R.Z. Valiev, A.V. Korznikov, R.R. Mulyukov, Materials Science and Engineering A 168 (2), 141-148 (1993)

[2] N. Tsuji, Y. Saito, S.H. Lee, Y. Minamino, Advanced Engineering Materials 5 (5), 338-344 (2003).

[3] R.Z. Valiev, R.K. Islamgaliev, I.V. Alexandrov, Progress in Materials Science 45 (2), 103-189 (2000).
[4] J.Y. Huang, Y.T. Zhu, H. Jiang, T.C. Lowe, Acta Materialia 49 (9), 1497-1505 (2001).

[5] T. D. Shen, C.C. Koch, Acta materialia 44 (2), 753-761 (1996).

[6] C.C. Koch, Nanostructured materials: processing, properties and applications, 2006 William Andrew, Norwich.

[7] A. Rosochowski, Solid State Phenomena 101-102, 13-22 (2005).

[8] W. Głuchowski, J. Stobrawa, Z. Rdzawski, Archives of Materials Science and Engineering 47 (2), 103-109 (2011).

[9] J. Stobrawa, Z. Rdzawski, W. Głuchowski, W. Malec, Journal of Achievements in Materials and Manufacturing Engineering 37 (2), 466-479 (2009).

[10] J. Stobrawa, Z. Rdzawski, W. Głuchowski, W. Malec, Archives of Metallurgy and Materials 56 (1), 171-179 (2011).

[11] W. Głuchowski, J. Domagała-Dubiel, J. Sobota, J. Stobrawa, Z. Rdzawski, Archives of Materials Science and Engineering 60 (2), 53-63 (2013).

[12] W. Kwaśny, P. M. Nuckowski, Inżynieria Materiałowa 205 (3), 102-106 (2015).

[13] W. Kwaśny, P. Nuckowski, T. Jung, Z. Rdzawski, W. Głuchowski, Technical Transactions Mechanics 110 (1-M), 214-219 (2013).

[14] A. Krishnaiah, U. Chakkingal, P. Venugopal, Materials Science and Engineering A 410-144, 337-340 (2005).

[15] F. Dalla Torre, R. Lapovok, J. Sandlin, P.F. Thomson, C.H.J. Davies, E.V. Pereloma, Acta Materialia, 52 (16), 4819-4832 (2004).

[16] K. Rodak, Rudy Metale R55 (9), 602-607 (2010). 